\title{
CAMINHANDO COM TARTARUGAS: SAGRADO, INFÂNCIA E OUTRAS ANALOGIAS
}

\author{
Gustavo Ruiz Chiesal
}

Dou respeito às coisas desimportantes

e aos seres desimportantes.

Prezo insetos mais que avióes.

Prezo a velocidade

das tartarugas mais que a dos misseis.

Tenho em mim um atraso de nascença.

Eu fui aparelhado

para gostar de passarinhos.

Tenho abundância de ser feliz por isso.

Meu quintal é maior do que o mundo.

Manoel de Barros

\begin{abstract}
Uma criança não olha para uma floresta e pensa: 'Ah, ai existe Clima, Biologia e existe também Geologia', certo? A criança simplesmente se move com a floresta, como os surrealistas fizeram, como o Bateson fez também.
\end{abstract}

Nora Bateson

1 Doutor em Ciências Humanas (Antropologia) pelo Programa de Pós-Graduação em Sociologia e Antropologia da Universidade Federal do Rio de Janeiro (PPGSA/UFRJ). Pesquisador de Pós-Doutorado (PNPD/CAPES) associado ao Programa de Pós-Graduação em Antropologia Social da Universidade Federal do Rio Grande do Sul (PPGAS/UFRGS). Contato: gustavorchiesa@gmail.com

Debates do NER, Porto Alegre, ano i 8, N. 3 I, P. 99-I I 2, JAn./Jun. 20 I 7 
Em muitas línguas ocidentais as palavras "sagrado", "santidade", "salvação", "saúde" e "saudável" apresentam raízes etimológicas bastante semelhantes (quando não as mesmas) que de algum modo se conectam às ideias de totalidade, inteireza ou integralidade (cf. Burkert, 1996). Como afirma Bateson (2006, p. 338), "o sagrado é algo que está peculiarmente vinculado ao saudável”. Uma infância saudável, na visão de muitos psicólogos e educadores, é um momento da vida em que o ser humano deve se sentir estimulado a exercer plenamente sua criatividade em brincadeiras, jogos, histórias e atividades que favoreçam a produção de relaçóes ou conexões entre seres, coisas, ambientes, sensaçóes, imagens e palavras muitas vezes impensáveis para um adulto "razoável".

O poeta Manoel de Barros parece estar certo ao sugerir que "a criança erra na gramática, mas acerta na poesia” quando, por exemplo, inventa palavras ou expressóes até entáo inexistentes (recordemos do menino Michel Leiris e de sua surpresa ao descobrir que seu "reusement" não estava correto, ou ainda, da exclamação "Bukta" criada por seu irmão mais velho), ou atribui novos significados às preexistentes (conectando coisas aparentemente "inconectáveis" como "Rebeca", "Meca” e "impeccable", ou "Moïse”, "Moisse", "Seine-et-Oise" e "oiser"). "Parecia que a linguagem estava como que torcida e que na mínima distância que separava os dois vocábulos [...] abria-se uma brecha capaz de deixar passar um mundo de revelaçôes", lembra Leiris em O sagrado na vida cotidiana.

Essa capacidade criativa que a criança (e também o poeta) tem de "torcer" (ou "dobrar", diria Deleuze) a linguagem e, a partir desse movimento de torção, alargar (ou "revelar") o sentido e a percepção de si mesmo (sua ontologia) e de seu próprio mundo (sua cosmologia) é algo que de alguma maneira nos permite estabelecer uma aproximação entre a infância e o sagrado. Ambos são poderosas forças que nos auxiliam no processo de "encantamento" do mundo, na busca pelo "maravilhoso", na habilidade para se "espantar" (Ingold, 2011) ou se deixar surpreender pelas pequenas coisas, pelas "insignificâncias do mundo e as nossas", diria o poeta Manoel. Aqui, vale pensar a infância não tanto como um período biológico ou uma 
fase da vida, e sim como um estado de espírito, um modo particular de perceber, experimentar e descrever as situaçóes cotidianas que independe de qualquer faixa etária. Um modo sagrado de caminhar pelo mundo, ou melhor, de se mover com ele.

A criança, ao caminhar pela rua, lembra Ingold (2015, p. 23), “é capturada por qualquer coisinha: da dança de luzes e sombras ao voo dos pássaros e latido dos cáes, do perfume das flores a poças d'água e folhas caídas, inúmeras pequenezas como caramujos e coquinhos, moedas perdidas e lixinhos reveladores". Como um "pequeno detetive" que se deixa levar pelas "pistas" que encontra em sua "investigação", a criança percebe a rua ou se engaja no ambiente com um olhar atento às sutilezas das pequenas coisas, suas diferenças e similitudes; um olhar "encantado, admirado e perplexo para tudo o que vê" (ibid.), mais interessado nas descobertas que sua caminhada pode lhe revelar do que no destino final que encerraria aquele movimento.

"Vagando à noite sem rumo certo" (Benjamin, 1994, p. 47), o flâneur, tal como a criança, também parece possuir essa capacidade de ser capturado pelos mínimos detalhes oferecidos pelo ambiente que habita, isto é, as ruas, as galerias, as feiras e os cafés das grandes cidades. Habilidoso observador da vida urbana e, por essa razão, também comparado ao papel desempenhado por um detetive, ele faz da rua o seu recanto sagrado, o lugar onde se sente verdadeiramente em casa. "A rua se torna a moradia do flâneur... [Os] muros são a escrivaninha onde apoia o bloco de apontamentos; bancas de jornais são suas bibliotecas, e os terraços dos cafés, as sacadas de onde, após o trabalho, observa o ambiente" (ibid., p. 35). Um ser que caminha pela cidade com o simples intuito de experimentá-la, esse é o flâneur na visão do poeta Charles Baudelaire. Crítico contumaz do "progresso da civilização", do processo de especialização provocado pela divisão do trabalho e da rotina massacrante fabricada pelo capitalismo industrial, responsável por automatizar e mercantilizar os sujeitos, o flâneur, como deliberada forma de protesto a esse modelo de sociedade, desfrutava de seu tempo livre, nos idos de 1840, levando tartarugas para passear pelas ruas e galerias parisienses, 
deixando "que elas lhe prescrevessem o ritmo de caminhar" (ibid., p. 51). Contrariando a velocidade e o automatismo imposto pelo capital, deveríamos aprender a caminhar com as tartarugas, devagar, a vagar e divagar, com a atenção voltada a tudo aquilo que nos cerca. Trata-se, mais uma vez, de um modo particular de perceber, experimentar e descrever as situaçóes cotidianas, uma outra maneira de apreender e de se movimentar pelo espaço urbano. Leitor atento da cidade e de seus habitantes, o flâneur não observa a multidão a partir de um ponto fixo e distanciado, ao contrário, ele procura se misturar nela, (con)viver e se (co)mover com ela. Tal como a criança que "simplesmente se move com a floresta", sem se preocupar em fragmentá-la em especialidades, subdivisóes ou taxonomias, ou como o poeta que preza mais "a velocidade das tartarugas que a dos mísseis", assim caminha o flâneur (e sua tartaruga) pela cidade.

"[...] Que cor tem para si a própria noção de sagrado", nos pergunta Leiris, ao final de seu ensaio. Tem cor de infância, cor de poesia, responderia a ele. Afinal, a criança, o poeta e, também, o flâneur estabelecem um tipo diferente de envolvimento sagrado com o ambiente. Eles possuem a habilidade para perceber e desfrutar o que se encontra ao seu redor, produzindo outras formas de pensar, sentir e contar aquilo que vivenciam. São pensamentos, sentimentos e narrativas atentas à inter-relação entre as coisas. Na história vivida e contada por Michel Leiris temos a compreensão de que o sagrado (na vida cotidiana) derivaria justamente do estabelecimento dessas relaçôes entre as coisas e os seres que se encontram num determinado ambiente (como, por exemplo, o banheiro onde ele e seu irmão se encontravam todas as noites para brincar e inventar histórias, lendas e personagens, ou ainda, o quarto de seus pais, território reservado e lugar da autoridade estabelecida). Os lugares, as coisas, os seres, as palavras, as histórias, os afetos, as lembranças, tudo, enfim, se constitui ou se define a partir de uma relação. Uma relação de semelhança - característica típica, como bem apontou Edilson Pereira (em artigo desse mesmo volume), não só do imaginário infantil, mas também do pensamento mágico - onde "qualquer coisa pode se assemelhar a outra”. Assim, na medida em que não se definem em si 
mesmas, é apenas na relação entre as coisas que poderemos de fato entender em que consistem tais coisas ${ }^{2}$. Nessa visão de mundo, tudo, em essência, tem a ver ou está conectado com tudo, e nosso papel seria justamente procurar descobrir qual o "padrão que liga" todas as coisas que compóem o universo. Que padrão, pergunta Bateson (1986, p. 16), “relaciona o caranguejo à lagosta, a orquídea à prímula e todos os quatro a mim? E eu a você? E nós seis à ameba em uma direção e ao esquizofrênico retraído em outra"? Relação, comparaçâo, correspondência e semelhança: bases de um pensamento mágico, analógico, surrealista e sistêmico; bases, acrescentaria, de uma percepção sagrada do ambiente.

O sagrado, desse modo, corresponderia ao estabelecimento de relaçóes de contiguidade ou, mais exatamente, à busca (recherche) criativa por essas associaçóes ou analogias entre as coisas, e não à ideia de que tais coisas existam a priori e sejam essencialmente sagradas. Os próprios espaços ou ambientes cotidianos se tornariam sagrados no momento em que passassem a ser sentidos, vividos, lembrados e/ou imaginados como um emaranhado de relaçóes ou de "fios vitais". Nos termos de Leiris, trata-se da passagem de um "estado comum" a um "estado privilegiado, mais cristalino, mais singular" ou, ainda, na transformação de um olhar "profano" para uma percepção "sagrada" da vida cotidiana.

Perceber a vida a partir de suas delicadas relaçóes de interdependência implica em rejeitar uma visão de mundo (e uma postura intelectual) que fragmenta a realidade e os próprios seres humanos em diferentes especialidades, disciplinas, hierarquias ou binarismos conceituais inventados pela modernidade. Implica, portanto, em rejeitar

2 Faço um uso proposital da palavra "coisa" inspirado no entendimento que Tim Ingold (2012a, p. 29) produz sobre ela, isto é, como um "agregado de fios vitais", um "acontecer" ou "um lugar onde vários aconteceres se entrelaçam, ou ainda, "um nó cujos fios constituintes, longe de estarem nele contidos, deixam rastros e são capturados por outros fios noutros nós". 
[...] que haja algo como a psicologia, que é diferente da sociologia, e algo como a antropologia, que é diferente das duas, e algo como a estética ou crítica de arte, que é diferente das duas, de todas as três, o que seja. E que o mundo é feito de pedaços separáveis de conhecimento nos quais, se você fosse um estudante, poderia ser examinado por uma série de questóes desconexas, chamadas de questionários de verdadeiro ou falso. O primeiro ponto que eu quero passar a vocês é que o mundo não é assim; mesmo! Ou, sejamos mais educados: o mundo no qual eu vivo não é de forma alguma assim, e quanto a você é da sua conta viver no mundo que você quiser (Bateson, G. apud Demarchi et al, 2013, p. 270).

Trata-se, num certo sentido, da produção de uma outra epistemologia ou, se quisermos, de uma nova sensibilidade estética atenta às formas, aos padróes, às semelhanças, às repetiçóes, às relaçóes entre tudo aquilo que compóe e caracteriza o "mundo vivo" que habitamos, sem "compartimentalizá-lo" em disciplinas autônomas. Afinal, lembra Nora Bateson (ibid., p. 208), "as disciplinas são construídas para serem separadas. Se você pedir a uma universidade para construir uma selva, você vai acabar tendo um departamento de répteis, um departamento de pássaros, um departamento de árvores e um departamento de águas". Tal floresta, acrescenta a cineasta, educadora e filha de Gregory Bateson, "não funcionaria de modo dinâmico e integrado".

Para o poeta romântico Johann Wolfgang von Goethe (apud Bateson, 1986, p. 25), "um caule é o que carrega folhas; uma folha é o que tem um broto num canto; um caule é o que foi uma vez um broto naquela posição". Nota-se que seu olhar está direcionado para a relação (ou "integração") e a ação (ou o "dinamismo") das coisas, inseridas num determinado contexto (ou "sistema”), e não para os seus atributos isolados. As definiçóes surgem, assim, por meio das "relaçóes entre caule, folha, broto, canto, e assim por diante" (ibid.), e não pelo que elas supostamente seriam em "si mesmas" (por exemplo, "uma coisa verde e plana", no caso da folha, ou "uma coisa cilíndrica”, referindo-se ao caule).

Outro poeta, o já mencionado Manoel de Barros, sugere que a infância é a melhor fonte de poesia que existe. A infância, diz ele, teria esse poder 
de dar novos comportamentos e significados às coisas, aos seres, às frases, às situaçôes... Quando, por exemplo, uma criança diz que "borboleta é uma cor que avoa [sic]", ou ainda, que "escutou a cor dos passarinhos", ela intuitivamente ultrapassa os limites estabelecidos pelo conjunto de regras gramaticais e ortográficas convencionais, deixando-se levar ou orientando sua atenção por outras "regras" mais próximas talvez da estética e da poética da vida cotidiana do que dos livros didáticos de língua portuguesa ${ }^{3}$.

A criança, diz o educador e escritor Antonio Severino, sente empatia com todas as coisas que encontra em sua caminhada; "com as pessoas que a rodeiam, com os brinquedos, com os bichos, com as plantas, com as pedras... para a criança, tudo tem vida, tudo tem alma... e ela pertence a tudo isso, ela faz parte de tudo isso" ${ }^{4}$. A criança (e, também, o poeta) estabelece uma relação de afeto com o ambiente, afetando e sendo afetada por todos os seres e coisas. Sentindo-se com o outro e como o outro, a criança parece materializar um modo de ser, conhecer e habitar o mundo (ou o seu "quintal", diria o poeta) que é profundamente relacional ou analógico.

Pensar por meio de analogias significa estar atento às semelhanças, correspondências e continuidades entre coisas, estabelecendo padróes que muitas vezes passam despercebidos num olhar ou uma leitura "desatenta" ou "negligente". Como lembra Ingold (apud Bonet et al, 2014, p. 307), inspirado n'O Contrato Natural de Michel Serres (1990), o termo religião deriva do latim relegere ou "ler novamente" que, num sentido medieval, significa "ser aconselhado pelo mundo, tomar conselhos do mundo, e daquilo que as pessoas dizem”. O contrário disso, ou seja, uma visão ou leitura não-religiosa da vida cotidiana, "não é o ateísmo, não é a falta de crença, e, sim, a negligência, negligere, não prestar atenção ao mundo, não ser aconselhado pelo mundo, náo estar preparado para aprender com as coisas que estão à nossa volta" (ibid.). Ingold, então, conclui que a religiáo ou a maneira

3 As frases citadas acima foram retiradas do filme "Só dez por cento é mentira: a desbiografia oficial do poeta Manoel de Barros”, de Pedro Cezar (2009).

4 Depoimento apresentado no filme "O começo da vida”, de Estela Renner (2016). 
religiosa/sagrada de perceber o ambiente envolveria, em última instância, uma questão de "comprometimento ontológico", onde ser e conhecer são partes constitutivas de um único processo de engajamento no mundo.

O historiador medievalista Hilário Franco Júnior aponta que o uso de analogias era algo estruturante do pensamento europeu durante a Idade Média, estando presente tanto na cultura "erudita" quanto na "vulgar" (Franco Jr., 2008). Rica em metáforas e analogias, a Bíblia serviu como principal fonte de inspiração (e imaginação) para o pensamento medieval, orientando não só a conduta moral dos indivíduos, mas também suas maneiras de perceber e agir no mundo. Exemplos não faltam: o homem justo, lembra o historiador ao citar passagens bíblicas (ibid., p. 3), "é como uma árvore plantada às margens de um curso d'água, dá frutos na época certa e sua folhagem nunca seca”; ele pede a Deus que "torne meus pés ágeis como os dos cervos e mantenha-me nas alturas"; ele define o Senhor como "meu abrigo, minha fortaleza, meu Deus em quem confio". Ou ainda, de maneira clara, temos Cristo, "o cordeiro de Deus que leva o pecado do mundo".

Seja por contágio (onde "as coisas que estiveram em contato continuam sempre a agir uma sobre a outra, mesmo à distância”) ou por similitude ("em que o semelhante evoca o semelhante, de modo que agir sobre um é agir sobre o outro"),

pensar por analogia significava estabelecer conexóes entre o mundo divino e o mundo humano, entre o Modelo e suas imagens. O universo era visto como uma grande rede de analogias porque na cultura cristã o ponto inaugural daquelas relações era evidentemente a Criação, que significa a presença, embora incompleta, de propriedades e formas do primum analogatum (Deus) nos secunda analogata, sobretudo no homem, feito 'à imagem e semelhança' Daquele (ibid., p. 6).

Pensadores cristãos medievais procuravam observar e interpretar a "grandeza" e a "beleza" da natureza (incluindo todas as suas criaturas) na intenção de melhor compreender a grandiosidade e a beldade Daquele que a criou. "Para Dioniso Areopagita, Deus é cognoscível graças às analogias das quais Ele é a causa; para Tomás de Aquino, toda Revelação se dá por analogia” (ibid., p. 5). Observava-se a natureza, acrescenta Franco Jr (ibid., p.

Debates do NER, Porto Alegre, ANo i 8, N. 3 I , P. 99-I I 2, JAN./Jun. 20 I 7 
14), "não em busca de leis naturais, causais, e sim de relaçôes comparativas e simultâneas". A analogia, nesse contexto, era uma leitura afetiva e dinâmica do mundo, almejando "identificar os elos entre os homens e deles com o universo". De fato, "para o homem medieval, Deus falava por analogias" (ibid.). De maneira semelhante, para Gregory Bateson, para os surrealistas e, também, para os esquizofrênicos, a vida opera por metáforas.

A metáfora é a lógica sobre a qual o universo biológico teria sido construído, afirma Bateson ${ }^{5}$; é, além disso, o ponto de contato entre a realidade e a imaginação, defendem os surrealistas.

Nem sempre é fácil perceber ou (re)conhecer a semelhança relacional entre coisas aparentemente desconexas. Tal atitude requer muita imaginação, uma enorme capacidade criativa; exige, portanto, uma "educação da atenção" (Ingold, 2010). E ao que tudo indica, nós não fomos treinados ou "aparelhados" para isso, diria o poeta Manoel de Barros. Ao contrário, nossa educação escolar, fragmentada em disciplinas, tende a adestrar nossa mente para que aprendamos a ver e definir as coisas pelo que elas são em si mesmas, isoladamente, e náo por meio de suas relaçóes com todas as outras coisas do ambiente. Perdemos, dessa forma, o sentido de unidade

5 Em "Os homens são como a planta”, Bateson (1990) discorre a respeito da metáfora e o mundo do processo mental, estabelecendo uma interessante comparação entre o "silogismo de Sócrates" (Os homens morrem. / Sócrates é homem. / Sócrates morre.), cuja lógica estaria assentada no sujeito e suas classes, e o "silogismo da planta" (As plantas morrem. / Os homens morrem. / Os homens são plantas.), comum ao modo de pensar dos esquizofrênicos, que remeteria à identificação dos predicados ("o que morre é igual àquela outra coisa que morre") e não mais dos sujeitos (no caso, o sujeito Sócrates sendo identificado primeiramente como homem e, por conseguinte, mortal). Para Bateson, a evolução biológica ou, mais exatamente, embriológica estaria baseada justamente nesse segundo tipo de silogismo, de caráter metafórico e relacional, que atualmente os biólogos e zoólogos chamam de "homologia". Notemos que a anatomia do corpo humano, bem como de todos os seres vivos, é rítmica, repetitiva e analógica: "o úmero no antebraço corresponde ao fêmur na coxa, o rádio-cúbito corresponde à tíbia-perônio; os ossos no pulso correspondem aos do tarso no pé; os dedos da mão correspondem aos dedos do pé" (Bateson, 1986, p. 16-7). 
capaz de conectar ou estabelecer (re)ligaçóes entre todas as coisas, criaturas e ecossistemas que compóem o mundo que habitamos. Algo grave, acrescentaria Bateson, porque coloca em risco não só a existência humana, mas também a existência de nosso planeta e de seus demais habitantes. Tal maneira de perceber a realidade, lembra o físico austríaco Fritjof Capra (1996, p. 217),

nos tem levado a tratar o meio ambiente natural - a teia da vida - como se ele consistisse em partes separadas, a serem exploradas comercialmente, em benefício próprio, por diferentes grupos. Além disso, estendemos essa visão fragmentada à nossa sociedade humana, dividindo-a em outras tantas naçóes, raças, grupos religiosos e políticos. A crença segundo a qual todos esses fragmentos - em nós mesmos, no nosso meio ambiente e na nossa sociedade - são realmente separados alienou-nos da natureza e de nossos companheiros humanos, e, dessa maneira, nos diminuiu. Para recuperar nossa plena humanidade, temos de recuperar nossa experiência de conexidade com toda a teia da vida. Essa reconexão, ou religação, religio em latim, é a própria essência do alicerçamento espiritual da ecologia profunda.

Contrariando essa lógica fragmentária e potencialmente destrutiva, Bateson proporá uma outra maneira de pensar, uma outra epistemologia, envolvida em mais afeto, humildade e sabedoria. Agir com sabedoria significa estar atento ao "sistema" de interaçóes como um todo, atento às suas relaçóes e transformaçóes, reconhecendo a dimensão sistêmica dos organismos, da vida e do mundo (Bateson, 1976, p. 296). Tais dimensóes ou "forças sistêmicas" podem ser chamadas de "mente" ou, ainda, "Deus". Agir com mais humildade e menos arrogância implica em perceber que nós fazemos parte desse sistema maior, que nós somos parte de "Deus", acrescenta Bateson. Trata-se, nesse sentido, de uma perspectiva "sagrada", atenta a unidade da vida, ao "padrão" que conecta todas as criaturas, responsável por gerar um sentido à própria existência. O sagrado, portanto, seguindo essa concepçáo, consistiria na dimensão integradora da experiência humana capaz de (re)estabelecer conexóes náo só entre os seres e as coisas que habitam o universo, 
mas também entre ser e ambiente, espírito e matéria, sujeito e objeto, razão e intuição, verdade e imaginação, sonho e realidade...

Para concluir gostaria de resgatar uma passagem do texto que serviu de inspiração para o título desse breve ensaio. Em Caminhando com dragóes: em direçâo ao lado selvagem, Tim Ingold (2012b) relata a história de um monge beneditino que, aflito com a vida monástica que levava, resolve deixar o mosteiro medieval onde vivia confinado. No entanto, ao sair, deu-se de cara com um enorme dragáo com a boca aberta, pronto para devorá-lo. Apavorado e tremendo de medo, ele gritou chamando por seus irmãos de monastério. Mesmo sem ver qualquer dragão, mas assustados com a expressão de pavor de seu colega, eles o levaram rapidamente para parte interior do monastério. Após aquela experiência impactante, daquele dia em diante, o monge nunca mais cogitou na hipótese de abandonar a vida monástica.

Nós, "modernos", talvez disséssemos àquele monge medieval que tudo aquilo não passou de uma alucinação ou um pesadelo produzido por sua mente de imaginaçáo bastante fértil. Algo, portanto, bem distante da realidade. Afinal, dragões não existem. Seus colegas medievais, porém, não afirmariam com tamanha certeza que aquele encontro com o dragão se tratou apenas de um simples sonho ou delírio. Certamente eles não acreditavam que dragóes (e outras criaturas semelhantes) pudessem existir enquanto seres pertencentes ao reino natural, mas em nenhum momento duvidaram que aquilo que o monge vivenciou fosse tão real quanto qualquer outra experiência capaz de gerar medo, angústia ou sofrimento. Logo,

quando o monge gritou para ser socorrido da boca do dragão, seus irmãos compreenderam que estava em apuros. Eles não reagiram ao seu suro - como psiquiatras modernos reagiriam aos delírios de um lunático que estivesse fugindo de um hospício - como idiossincrasia, possíveis alucinaçóes induzidas por drogas, de uma mente febril e inquieta. Em vez disso, eles imediatamente reconheceram a visão do dragão na forma inarticulada do monge (Ingold, 2012b, p. 18). 
Sem tratar como algo irreal ou inexistente, eles, de fato, levaram a sério a experiência vivida pelo monge. Esse último, por sua vez, de acordo com a história relatada, já estava sendo acompanhado pelo dragão há algum tempo, fato que explicaria suas dúvidas e incertezas em relação às suas escolhas religiosas e existenciais. No entanto, ele só conseguiu perceber o dragão no momento em que deixou de olhar unicamente com os sentidos físicos e passou a adotar, de forma intuitiva, uma outra percepção, um outro modo de ver (e imaginar) a realidade. Uma atitude ou uma maneira sagrada (e saudável) de perceber e participar do mundo, capaz de transformar ou de atribuir novos sentidos à vida cotidiana.

Assim, ao propor que caminhemos com os nossos dragóes, Ingold sugere que aprendamos a lidar com a imaginação de uma maneira mais adequada, mais equilibrada, sem negá-la em sua existência ou separá-la do mundo, tal como fizera a moderna ciência ocidental, de modo que tais dragóes apresentem um tamanho "mais sustentável”. Tal caminhada envolve o exercício de uma leitura, de um olhar ou de uma epistemologia que seja capaz de nos religar ou de nos ensinar a ler novamente o mundo. Envolve, além disso, a produção de uma leitura e de uma escrita sagrada que de algum modo procura levar um pouco mais de poesia para a nossa prosa acadêmica. Envolve, finalmente, que também aprendamos a caminhar com as tartarugas, pois só assim - quando aprendermos a caminhar um pouco mais devagar e com a atençáo voltada para as "insignificâncias" da vida - seremos capazes de perceber aquilo nos cerca de uma outra maneira, com outros olhos, outras lentes, talvez mais analógicas, ou menos digitais que as atuais lentes que costumamos utilizar.

\section{REFERENNCIAS}

BARROS, Manoel de. Poesia Completa. São Paulo: LeYa, 2013.

BATESON, Gregory. Pasos hacia una ecología de la mente. Buenos Aires: Ed. Carlos Lohlé, 1976. 
- Mente e Natureza: uma unidade necessária. Rio de Janeiro: Francisco Alves, 1986.

. Os homens são como a planta. In: THOMPSON, William (Org.). Gaia: uma teoria do conhecimento. São Paulo: Editora Gaia, 1990.

- Una Unidad Sagrada: pasos ulteriores hacia uma ecología de la mente. Barcelona: Gedisa, 2006.

BENJAMIN, Walter. Charles Baudelaire: um lírico no auge do capitalismo. (Obras Escolhidas, v. III). São Paulo: Brasiliense, 1994.

BONET, Octavio et al. A antropologia como participante de uma grande conversa para moldar o mundo: entrevista com Tim Ingold. Sociologia \& Antropologia, v. 4, n. 2, p. 303-326, 2014.

BURKERT, Walter. Creation of the Sacred: tracks of Biology in early religions. Cambridge: Harvard University Press, 1996.

CAPRA, Fritjof. A teia da vida. São Paulo: Cultrix, 1996.

DEMARCHI, André et al. 2013. Uma conversa sobre ecologia da mente: entrevista com Nora Bateson. Enfoques, v. 12, n. 1, p. 266-283, 2013.

INGOLD, Tim. Da transmissão de representações à educação da atenção. Educação, v. 33, n. 1, p. 6-25, 2010.

. Being Alive: essays on movement, knowledge and description. New York/London: Routledge, 2011.

INGOLD, Tim. Trazendo as coisas de volta à vida: emaranhados criativos num mundo de materiais. Horizontes Antropológicos, v. 18, n. 37, p. 25-44, 2012a.

. Caminhando com dragóes: em direção ao lado selvagem. In: STEIL, Carlos Alberto; CARVALHO, Isabel (Org.). Cultura, percepção e ambiente: diálogos com Tim Ingold. São Paulo: Terceiro Nome, 2012b. 
O dédalo e o labirinto: caminhar, imaginar e educar a atenção. Horizontes Antropológicos, v. 21, n. 44, p. 21-36, 2015.

FRANCO JR, Hilário. Modelo e imagem: o pensamento analógico medieval. Bulletin du centre d'études médiévales d'Auxerre, n. 2, p. 1-29, 2008.

SERRES, Michel. O Contrato Natural. Lisboa: Instituto Piaget, 1990.

Recebido em: 10/12/2016 Aprovado em: 20/02/2017 